\title{
Significance of the application of ionomer-VO polymer in the fight against irrational erosion and its scientific justification
}

\begin{abstract}
Promotional value of the polymer ionomer - VO to combat erosion, irrigation and its scientific basisThe article describes the use of polymers inomera- VO irrigation to combat erosion. This all laid field experiments on the tomato (tomato) in the soil of Absheron district. Experiments werw 3 -fold to 4 embodiments. In stationary conditions we have studied the effect of different liquid polymers iononomers-5 speeds of syrup, solid flow, depth and width of gum powder, 5 mechanical compositions and structured -decorative characteristic of soil-aggregate.It was found that, in connection with the use of ionomera-VO decreases the speed of molasses, as well as a solid stock. Further improvement of the nutrients, as well as the mechanical composition and structures of the alluvial-meadow soils on an example of Apsheron district. Recommended application ionomera - $\mathrm{VO}$ on plantings of tomato (tomato).
\end{abstract}

Keywords: irrigation erosion, polymer-VO, soil moisture, fluid flow, flow flow, flow velocity
Volume 2 Issue 6 - 2018

\author{
ZH Aliyev \\ Institute of soil science and agrochemistry of NAS of Azerbaijan, \\ Azerbaijan \\ Correspondence: ZH Aliyev, Institute of soil science \\ and agrochemistry of NAS of Azerbaijan, Azerbaijan, Email \\ zakirakademik@mail.ru
}

Received: August 18,2018 | Published: December 19,2018

\section{Anatation}

The importance of Ionomer-VO polymer in the fight against irrational erosion in stationary conditions. The study showed that irrigation erosion was eliminated as a result of application of $0.20 \%$ ionomer-VO polymer with $150 \mathrm{~kg}$ per hectare, agro-physical properties of aggregate soils and agrochemical content improved.

\section{Introduction}

The favorable soil and climatic conditions of the Republic of Azerbaijan have allowed to develop many areas of agricultural agriculture (grain growing, cotton growing, horticulture, vegetable growing, gardening, potato growing, poultry farming, etc.). Vegetablegrowing is one of the foundations of the agricultural production industry, which has been widely developed in the Absheron zone, as in other regions of our republic. In the country, vegetable crops are mainly used for deserted soils and landslides. These soils are composed primarily of lightweight and gray casing according to their mechanical composition, and this production area is of great importance in terms of their erosion resistance. For this purpose during the 2011-2014 research period, the importance of application of the "Importance of application of Ionomer-VO polymer in the fight against irradiation erosion under various crops and proportions under tomato cultivation and its scientific justification" was investigated and investigated.The tomato plant is one of the strategically important agricultural varieties that have been historically registered in Azerbaijan, which has been developed and brought to the soil by soil, and has been cultivated from the long history in the country. This plant is also the main raw material for the agricultural production industry, but is also considered to be profitable compared to other predecessors. As is known, currently, the tomato plant is grown and grown in greenhouses through its seeds, first of all in terms of environmental safety. The tomato seedlings found here are transferred to the fields after they are transferred to 3-4 branching phases. At this time, the tomato seedlings must be solid $(13-15 \mathrm{~cm})$ in height, but also healthy. Tomato seedlings are grown in a well-prepared soil in the range of $70 \times 30 \mathrm{~cm}$. First, planting then reinforcing, and later vegetable watering (at least 4-5 times) in the area. The rate of watering in irrigation and the speed of water in the grass is considered to be the basis. Otherwise, the soil is easily exposed to irrigation erosion. Therefore, it is important to increase their erosion resistance.

\section{Research object and methodology}

The field experiments on the importance of the fight against irrigation erosion of the ionomer-VO polymer under tomato plant planting were conducted in irrigated land areas spread in the territory of Pirshagi settlement of Absheron district. For this purpose, fieldfield practices have been implemented in 4 variants and each with 3 repetitions. The water soluble solution in the amount of 50,100 and $150 \mathrm{~kg}$ will be given to each hectare before 1:10, and the ionomerVO polymer sprayer was sprinkled into the bowl of the tomatoes that were planted before each irrigation. Here, the flow of water is determined on the basis of the soil samples taken from the soil weight and the amount of soil (with samples taken after filtration), with biometric measurements not less than 3 (tomato plant rich, technical the amount of leaves that are useful in the field) and the productivity of the plant has been determined. Mechanical, structural-aggregate and some agrochemical composition of the field of soil of the field for the study of soil slices, based on samples taken on the basis of the weight of the method of hychroscopic moisture, Kachinsky method by mechanical composition, NI Savvinov method of structureaggregate composition, humus IV .According to his estimation, the total nitrogen is determined by PBProtasov, which is the exchange of potassium, according to the biologically active phosphorus - BPM, by the Kueldal method. In recent years, the development of chemistry science There has been great achievement in the development of organic chemistry, one of its integral components, which has been reflected in the creation of ionomer-VO polymers used in our practice. It should be noted that the substance of these substances consists of several million different molecules of chemicals, some of which are several million to several million. The polymers are naturally derived from their origin (eg proteins, nucleic acids, natural resin) and synthetic polymers (eg polyethylene, polypropylene, formaldehyde resins and so on). Unlike natural polymers, synthetic polymers are 
widely used in industry and everyday life, as well as in some areas of agriculture. Examples include K-4, K-9, latex, Poni-Q, pomid SP-8 copolymer, QAFS-17, HPAM, OKL (hydrolysis), AY (ammonium carbonate), ammofox, OY, OY-vu and others. This polymer is widely used in agriculture as well as in some areas of the national economy. In agriculture, mainly irrigated and mechanical composition has been used to protect irrigation erosion in unstructured lands with light and sandy content, as well as protecting moving sands from wind erosion. Detailed information on this is provided by, ${ }^{1-6}$ LASulakova et al. ${ }^{7}$ XMMusafayev et al. and others. not only because we do not need to give a full explanation of the works of the above-mentioned researchers, but also to show that these researchers have mainly tested polymers such as K-4, K-9, and latex-like stabilizing stimulants. They determined that as a result of the application of the polymers mentioned above, water-physical, physical properties, mechanical and agrochemical components of the soil have a positive effect on the improvement of the control areas and, mainly, elimination of irrigation and wind erosion. As can be seen from the polymer studies, especially the ionomer-VO polymer. In this regard, we have been conducting research on the ionomer-VO polymer synthesized by the Institute of Chemical Processes of the Azerbaijan MEA, created by the Institute of All-Union Scientific Researchers (Baku) Institute. It should be noted that the composition of this polymer is $5-7 \%$ solution of polyacrylonitrile-hydrolyzed sodium, consisting of light yellowish, viscous constants, well-soluble condensate.

Each polymer of the polymer is $0.05 \%, 10 \%$ and $0.20 \%$ solution was prepared and a substantial research work was carried out under the tomato plant in the field of AR ETM ET Vegetable Production Institute. Important results have been achieved and recommended for large-scale application in the country. the experimental area was selected, before planting there was an ice-cream pail in autumn, and again in the early spring, the plowing was done. Below you will find information about the options available in stationary conditions and the indicators that belong to them. Control-non-ionomer-VO polymer; 2 . Ionomer-VO polymer is a water soluble soluble solution of $0.05 \%$ by weight of $150 \mathrm{~kg}$ per hectare; The Ionomer-VO polymer is a solution of $0.10 \%$ soluble solids with a total content of $150 \mathrm{~kg}$ each; The Ionomer-VO polymer is $0.20 \%$ water soluble solution with a weight of $150 \mathrm{~kg}$ perha, $0.22 / \mathrm{sec}$. water consumption has been applied. Experiences have been implemented with three repetitions. The ionomer-VO polymer was sprinkled with sprinkler in the cherry pit. The pomegranate seeding was carried out on a $70 \times 30$ scheme. The area of repetitive experiments covered a total area of $183.6 \mathrm{~m} 2$ with a total area of $14.7 \mathrm{~m} 2$ (width 1.7, length $27 \mathrm{~m}$ ). Except for controllable variants, the soil was softened at a depth of $0-10 \mathrm{~cm}$ before application of the ionomer-VO polymer and at $0: 10$ to $1: 10 ; 0.10$ and $20 \%$ ionomer-VO polymers were sprayed. In the course of the research, four times a year, vegetation irrigation was performed. First, the flow rate, the flow of flow, the soil moisture, the washing of some nutrients (humus and $\mathrm{K} 2 \mathrm{O}$ ), and the effect of the ionomer-VO polymer in the mechanical composition of the soil have been investigated. Studies have shown that, with the introduction of the ionomer-VO polymer, the flow rate of the water is considerably improved on the average, with three rinsing cycles. Thus, if the water flow rate is $0.80 \mathrm{~m} / \mathrm{sec}$ in the control variant, this indicator is $0.40 \mathrm{~m} / \mathrm{sec}$ in the $0.05 \%$ solution of the ionomer-VO polymer, variants with $0.10 \%$ a $0.30 \mathrm{~m} / \mathrm{sec}$, and $0.20 \mathrm{~m} / \mathrm{sec}$ in a solution of $0.20 \%$ solution. Influence of the polymer on the flow rate of the polymer of the polymerTorpagin Name of the site
Irrigation method Variants Slaughtering norm, $\mathrm{kg} / \mathrm{ha} / \mathrm{The}$ content of the solution, percentage of water in the water Three abrasive medium I II III Alluvial open-loaf 0,052 First- 4 0,6 0,5 0,80 0,052 Second with Scenario 150,0 0,05 0,5 0,4 0,4 0,40 0,052 Third 150,0 0,10 0,2 $0,30,30$ with Scenario , 30,052 Shimla Fourth 150,0 0,20 0,1 0,2 $0,20,20$ These indicators are clearly evident from the impact of the flow of flow from the ponds depending on the effect of the ionomer polymer. The filtration process revealed that the amount of flow of fluid depends on the variants of the experiments, as well as on the rate of delivery of the ionomer-VO polymer.

After three rinses, $0.20 \%$ ionomer-VO polymer was given in the highest flow rate control option $(12,70 \mathrm{q} / 1)$, at least $(3,60 \mathrm{~g} / \mathrm{l})$ and 150 $\mathrm{kg}$ per hectare. Thus, in the variant 0.20 Ionomer-VO polymer with $150 \mathrm{~kg}$ each, the amount of flow of stream after reduction of three times compared with the control decreased to $3.5 \mathrm{~g} / \mathrm{l}$. Table 2 Effect of the Ionomer-VO polymer on the peat flow Field irrigation Method of irrigation Probability of the product Seed norm, $\mathrm{kg} / \mathrm{ha}$ Composition of the solution Percentage of irrigation Ivory III from Ivorysurvey III Alluvial open-loaf 0,052 Firstwind (control) - 11,20 12,50 14,50 12,70 0,052 Shrimp Second 150,0 0,05 6,20 7,60 6,70 6,80 0,052 Third 150,0 With Scenario 0,10 3,80 4,70 5,50 4,70 0,052 Fourth with Scorpio 150,0 0,20 2, $903,904,103,60$ Such a law has been the same for other land indicators. Thus, in the case of irrigation bottles resulting from the effects of all watering irrigation, the width of the irrigation bottles is $12.0 \mathrm{~cm}$ in the experimental version of ionomerVO polymer with $12.0 \%$ solution per 150 hectares, with a width of $5.0 \mathrm{~cm}$ these indications did not exceed 3.5 and $2.0 \mathrm{~cm}$, respectively, or the amount of humus that was washed with fluid flow at $47 \%$, and with a flow of such a chemical compound of $0.78 \%$, with a flow of fluid every ha-a $150 \mathrm{~kg}$ The $0.20 \%$ ionomer-VO polymer dispersed in these variants showed a decrease of $0.21 \%$ and $0.37 \%$ respectively, the amount of physical clay contained in the mechanical particles of the soil was $46.80 \%$, the quantity of luminescence particles was 8 , In the case of $00 \%$, the ionomer-VO polymer in the form of a $0.20 \%$ solution (each ha-a $150 \mathrm{~kg}$ ) is $48.00-48.40$ and $9.20-9.600 \%$ In addition to the above, samples were taken and analyzed to study the effect of the ionomer-VO polymer on the structure-aggregate composition of the soil in the field-stratified survey. Studies have revealed that the ionomer-VO polymer has a $0.20 \%$ In the solution variant, the structural particles of $1 \mathrm{~mm}$ at the top layer of soil $(0-5 \mathrm{~cm})$ were $93.4 \%$, while this parameter decreased to $90.6-84.9 \%$. However, the amount of water-resistant aggregates in the control was found to be an average of 3 times more aggregate than $0.20 \%$ in comparison with the controlled 11.7. However, the soil weight decreased from $1.23 \mathrm{gr} / \mathrm{cm} 3$ to $1.11 \mathrm{gr} / \mathrm{cm}$, and the total porosity of the soil increased from $47.5 \%$ to $57.6 \%$. With the application of Ionomer-VO polymer, the development of irrigation erosion has also been eliminated with the improvement of water-physical properties and agrochemical composition of soil. All this has had a positive effect on the size and development of the tobacco plant cultivated in the field of practice. The biometric measurements taken on the tobacco plant and the account of the product have been shown more clearly. Thus, if the tobacco plant in the tobacco plant is not applied to the ionomer-VO polymer, the average height of the tobacco plant is $1.34 \mathrm{~m}$, and its stems on the body are 11 , with a $0.20 \%$ ionomer-VO polymer containing 150 $\mathrm{kg}$ per hectare the height of the plant was $2,10 \mathrm{~m}$, and the number of leaves on its body increased to 25,0 . The productivity of the plant was $17.0 \mathrm{~s} /$ ha in the control area, ionomer-VO polymer in the form of 
$0.20 \%$ solution with a weight of $150 \mathrm{~kg}$ per hectare, and this figure was $27.0 \mathrm{~s} / \mathrm{ha}$. These indicators demonstrate the importance of the ionomer-VO polymer in the alluvial open-plain soils in the form of a $0.20 \%$ solution of $150 \mathrm{~kg}$ per hectare.

\section{Results}

The effect of the ionomer-VO polymer to fight irrigation erosion in the alluvial open-plain soils spread in the Absheron region was investigated. Research has shown that as a result of the application of ionomer-VO polymer in the $0.20 \%$ solution of $150 \mathrm{~kg}$ per hectare, In the open grassland, flow velocity decreases significantly, relative to the relative flow of the flow, considerably decreases the soil's moisture content Growth, physical properties, agrochemical composition improves. Considering the positive aspects of the polymer of the polymer, it is recommended that the polymer be used as a $0.20 \%$ solution of $150 \mathrm{~kg}$ per hectare before the polymer's watering.

\section{Acknowledgments}

None.

\section{Conflicts of interest}

Author declares that there is no conflict of interest

\section{References}

1. Adventure B. Problems of artistic structuring. Sat Trin Agrophysics. 1960(8).

2. Matsunin NF. Polymers in irrigation erosion. J Crunchy. 1961(1).

3. Mahli. The high polymer for the steak and smushes. Desis Ha axle. 1966.

4. Makhsudov HM. Eroded cerebral pumps and their productivity. Tashkent. Search FAN. 1981

5. Paganyas KR. Optimization of the basic properties and modes of typical cerebral palsy in the art of structuring. Tashkent. Search FAN. 1982 .

6. Gulmamedov RG. Exploration of wind erosion and evolutionary barriers with the Absheron. Handwriting. 1960.

7. Sulakova LA, Burakovskaya Ye, Amiraslanov GZ. Oblique obstruction of the polymer preparations. Tr. NI Sector Erosia T YV; 1970. 